\title{
Global Transformation Towards Sustainability-Clusters of Current Scholarly Discourse
}

Studying global transformation towards sustainability is a colossal task. The difficulties in determining the scope, boundaries and levels of the analysis have ramifications for the conceptual value of attempts to understand global transformation towards sustainability. Because of the plurality of possible entry points as well as the complexity of various issues involved, providing an overview of the academic debate, if one can speak of a single debate on global transformation towards sustainability, is highly challenging. Hence, ensuring the 'epistemological acuity' of transformation towards sustainability is still in its elementary stage. Linking the debate of transformation or transition with the studies of sustainability has its own merits, but it also leads to further fragmentation of the debate. Moreover, without a clear definition of the normative concept "sustainability" as the goal of transformation/transition or the scope of conceptual analysis, designing and verifying methodologies becomes equally multifaceted. This blurriness implies that gaps will most likely arise during the calibration of theoretical and empirical models. Furthermore, the plurality of methodologies, for example, will most likely lead to many different types of mutually complementing and competing evidence. 
When the term "sustainability" entered various policy circles, both on the global and national scale, the proliferation of interpretations and responses, especially with the absence of verification mechanisms, inevitably call for flexible approaches. In this regard, as the US Natural Science Foundation (2000) contends, the term 'sustainability' is laden with so many definitions that "it risks plunging into meaningless(ness), at best, and becoming a catchphrase for demagogy, at worst. It is used to justify and legitimate a myriad of policies and practices ranging from communal agrarian utopianism to large-scale capital-intensive market development." Therefore, because of the existence of many possible definitions (Hopwood et al. 2005b) and divergent interpretations and variations applied in practice (Gibson 2005), sustainability has become an "overused misunderstood phrase" (Mawhinney 2002). With the intention of providing a useful overview of the academic literature, this chapter synthesizes the debates on transformation towards sustainability by developing a detailed characterization of drivers, actors and barriers to change as well as an overview of potential anchors for deliberations. Table 2.1 illustrates the different identified clusters and compares them in terms of context (offering a systems perspective by focusing on entry points and drivers), agency (addressing power and purpose by highlighting anchors for a deliberation process), and audience (in reference to legitimacy and social contract vis- à-vis a transformation process). 


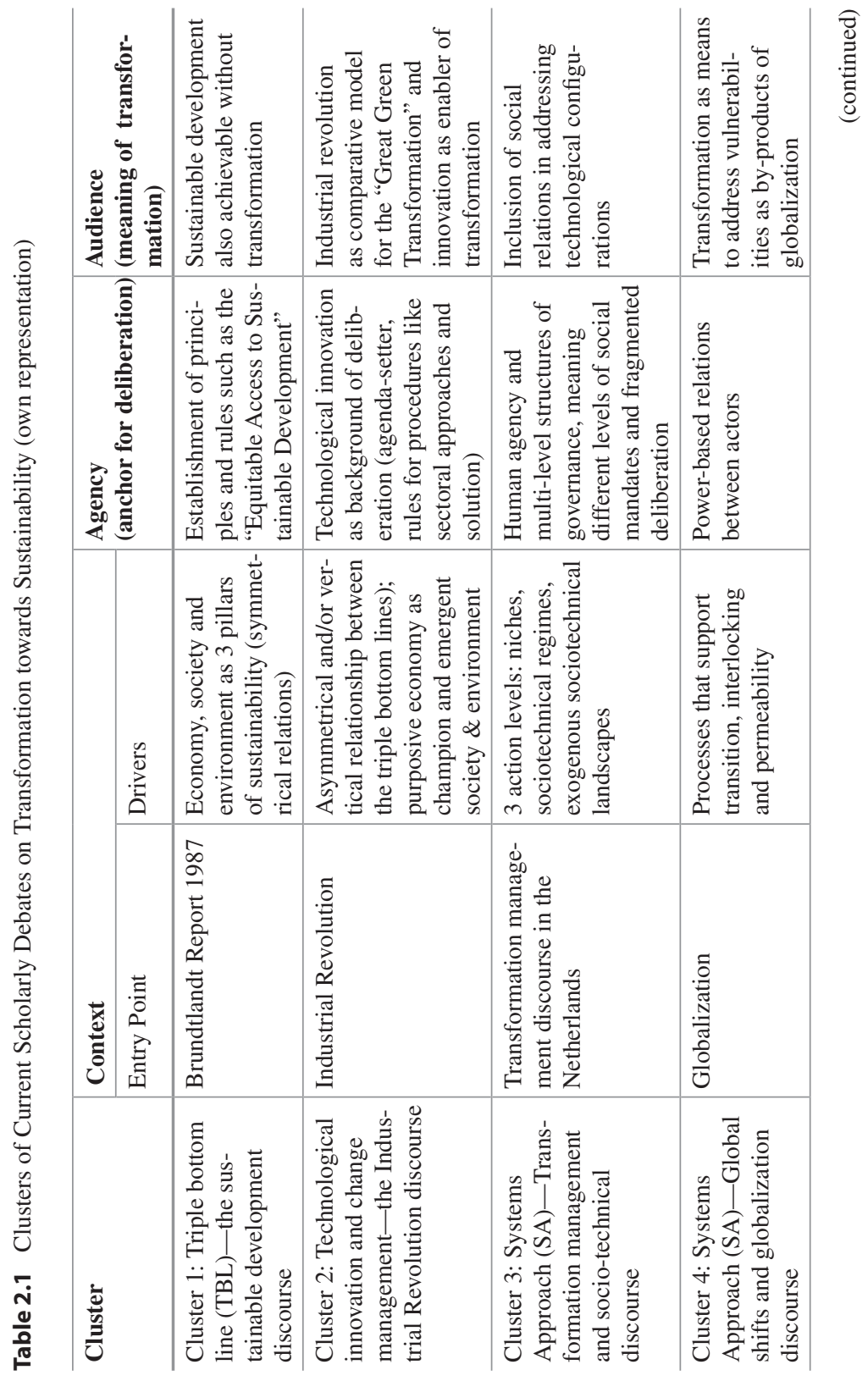




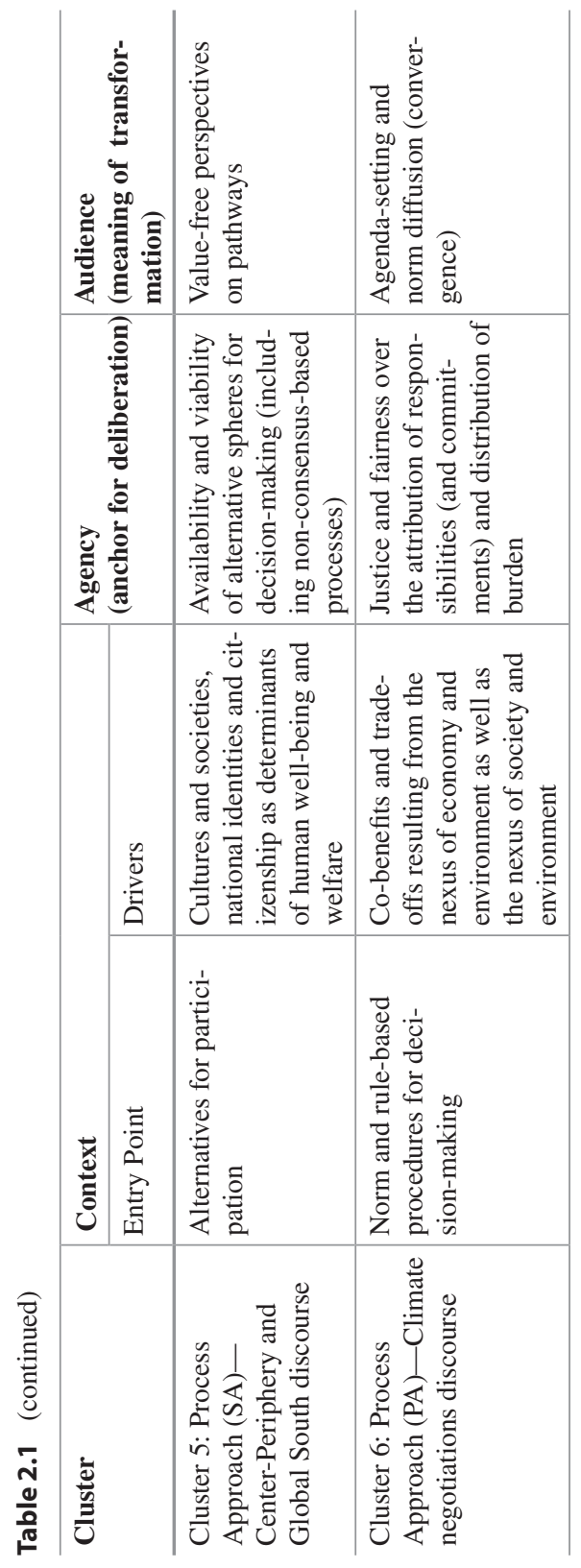




\subsection{Cluster 1: Triple Bottom Line (TBL)-The Sustainable Development Discourse}

The literature categorized in the cluster Triple Bottom Line (TBL) refers to the sustainability and developmental discourses that evolve around the Brundtland Report in 1987. The literature on sustainable development has achieved a consensus about the three pillars of sustainability-social, environmental and economic (see Byrne \& Glover 2002; Hopwood et al. 2005b; Elliott 2013). They were inherited as these three categories—later labelled as the Triple Bottom Line-and have been standardized in most UN agencies addressing sustainability since the 1980s. The Triple Bottom Line, originally introduced by John Elkington (1994, 1997) is an accounting framework traditionally used in economics and business administration that refers to the society, the environment (ecology), and economy (see Willard 2002; Savitz 2006; Slaper, Timothy \& Hall 2011).

The TBL has functioned as a catalyst for the sustainability debate, whereas social cohesion, environmental integrity and economic affluence are taken as goals toward which transformation processes are heading. The usage of TBL as a framework was institutionalized by the public sector when it was used as the cost accounting standard by the International Council for Local Environmental Initiatives (ICLEI), which was founded in September 1990 at the United Nations in New York. This international association has more than 1200 cities, towns, and regions from 84 countries as members (ICLEI 2018). The private sector has followed the TBL accounting standard and used the phrase "people, planet and profit" as the goal of sustainability, which later framed the elements of corporate social responsibility for companies wishing to embody these three Ps. Subsequently, as climate change negotiations have produced the principle of "Equitable Access to Sustainable Development" as a major anchor for any acceptable climate agreement, these TBLs have been incorporated into most discussions about transformative pathways.

Because of the functional importance of sustainable development in achieving climate mitigation, this cluster highlights the perspective of sustainable development through transformation. However, from this perspective, environmental integrity (i.e. climate mitigation) is only one of three equally important pillars. The distinct origin and constitution of the debate on sustainable development limits the capability of this discourse (cluster) to support the overall discussion on climate mitigation. The actors participating in the debate on sustainable development are diverse, probably too diverse for the climate regime. Furthermore, as will be highlighted in this cluster, sustainable development can also be achieved without transformation. This is in contrast to the discourse on climate mitigation, 
wherein transformation (labelled as 'transformative pathways') is inevitable and a precondition. Those from the public and business sectors in particular belong to the "weak sustainability" group (see Solow 1974; Hartwick 1977; Solow 1986). They argue that sustainable development can also be reached without major structural changes that require insurmountable sacrifices. In contrast, proponents of strong sustainability view the natural system as intrinsically valuable and not substitutable (see Brand 2009; Dedeurwaerdere 2014). Hence, there is a hierarchy of norms between the natural/environmental and human system.

Bill Hopwood et al. (2005b) classify debates on sustainability into three schools-status quo, reform and transformation, which strongly correspond to the categories of weak and strong sustainability. According to them, the "Status Quo School" is the dominant view of most governments and business groups. Those belonging to the Status Quo School tend to be proponents of weak sustainability who see economic growth as the solution to addressing climate change. For example, the Green New Deal Group, through its published report on July 21, 2008 (Green New Deal Group 2008) calls for a "return to pre-war Keynesianism" and an increase in public investment spending and international finance to address climate protection (Lynas 2008). Other notable proponents such as Thomas Friedman (2007), Mariana Mazzucato (2015), Van Jones (2008), the Heinrich Böll Foundation of Germany (French et al. 2009) advocate for fiscal policies that provide stimulus packages to address both financial crises and environmental issues such as climate change.

The combination of fiscal instruments such as investment in the deployment of renewable energies and the enhancement of resource efficiency is the solution (French et al. 2009). Edward Barbier (2009) published the report "Global Green New Deal" which was commissioned by the United Nations Environment Programme (UNEP). The report calls on governments to allocate a significant share of stimulus funding to green sectors order to achieve economic recovery, poverty eradication and climate protection through reduced carbon emissions.

Bill Hopwood et al. (2005b) continues with the "Reform School," which is the dominant view of academic communities and mainstream NGOs. The "Limits to Growth" report of Donella Meadows et al. (1972) is often considered to have initiated challenges to the idea that growth was the only way to improve environmental integrity. Subsequent authors and environmental groups such as Friends of the Earth, Greenpeace, WWF and Sierra Club have voiced their concerns about economic growth as the generic solution through political lobbying (Hopwood et al. 2005b). Other proponents of the Reform School attribute the root of the problem to imbalances and a lack of knowledge and information. For example, the Real World Coalition, a group that consists of 25 UK NGOs, sees 
the necessity of revitalizing democratic governance to empower the government and society to address mounting inequality and poverty, environmental degradation and world instability (Christie \& Warburton 2001). This school also suggests there is a need for significant shifts in policies and behavior. In their book "Factor Five," Ernst Ulrich von Weizsäcker et al. (2009) suggest that sustainability can be achieved by improving resource productivity for some sectors of the economy, while maintaining quality of service and well-being. This argument for using technological solutions partly contradicts the Status Quo School by suggesting a significant degree of degrowth, particularly in consumption and production.

The Third School, as Bill Hopwood et al. (2005b) elaborate, sees transformation as fundamentally necessary to avoiding a mounting crisis and even a possible system rupture. Linking this cluster to the global transformation towards sustainability debate, it is implied that this cluster sees transformation as only one of the options and that sustainability can also be achieved without transformation. Authors that tend to represent the "Transformation School" call for "strong sustainability." This school is the dominant view of grass-root environmental justice groups and indigenous environmental movements. For most of these groups, there is a need for a new system and a new distribution of power (a shift from center to the periphery) (O'Riordan 1989). For the others, there is a need to re-visit the dogmatic realization of growth, whereas the logic of growth is considered the essence of economicity (Bonaiuti 2014). Because fundamental problems as well as imbalances are deeply rooted in society, more efforts and commitments are needed to address the conditions that produce and reinforce imbalances.

The Transformation School is also represented by views that are counterintuitive or even counterfactual to the goals of global transformation towards sustainability. In fact, extreme "transformationists" such as socialists, deep ecologists, and eco-fascists are not concerned with sustainable development. Other proponents belong to what some have called the "School of Post-development," from which the "partisans" of degrowth or "growth objectors" have originated (see Bonaiuti 2014). For example, David Foreman (1989), one of the founders of Earth First!, justifies the starvation of people in Ethiopia as nature's way of self-preservation (quoted in Bradford 1989; Hopwood et al. 2005b). In addition, Arne Naess (1989) observes that in the eight points of the deep ecology platform, human needs are sacrificed, and equity concerns ignored.

Nevertheless, this Transformation School also represents "transformation with sustainable development." One example is the Report of the German Advisory Council on Global Change (WBGU) (2011) that argues that transformation is a constant development brought about by changes. As new problems emerge, societies seek solutions. In most situations, these solutions require systemic or 
structural changes to alter the obsolete conditions that have caused the problems in the first place. For example, after analyzing the tendency of returns on capital to exceed the rate of economic growth, leading to extreme inequalities, Thomas Picketty (2014) argues that "economic trends are not acts of God." Hence, political actions are needed to design and implement social policies that reduce inequality and do not grow the GDP for its own sake. It is therefore implied that transformation is not only emergent, i.e. merely a response to changes, but also purposive, i.e. transformation goals are pre-determined. In addition, as the WBGU (2011) continues, advancing sustainable development will not only require modifications to social contracts as a means of adapting to changes, but new social contracts will most likely also challenge existing governance structures, for instance, because of the transboundary nature of vulnerabilities. More arguments from the Transformation School will be introduced in the Cluster on the Multi-Level Perspective.

\subsection{Cluster 2: Technological Innovation and Change Management-The Industrial Revolution Discourse}

While the discourse that belongs to this cluster uses the triple bottom lines as levels of analysis, its focus also lies in the linkages between them, particularly in the analysis of the effects of innovative and technological changes on small organizations such as industrial and commercial companies (Kristof 2017). Furthermore, there is an implied asymmetrical or vertical relationship between them, with the economy receiving the primary focus. The common denominator in the literature included in this cluster is the use of the Industrial Revolution as a comparative model or as precedent that frames the analysis of the scope and processes behind the "Great Green Transformation." For example, Tom Delay (2009) argues that the low carbon economy will transform the world much like the first industrial revolution did.

The Industrial Revolution from about 1760 to $1820 / 1840$ was driven by technological innovations, which led to new manufacturing and production processes as well as commercial relations between countries (see Hobsbawm 1965; Landes 1969; Reisman 1998). The unprecedented, sustained economic growth throughout the Industrial Revolution is claimed to have marked a major turning point in history that changed almost every aspect of society (see Feinstein 1998; Lucas 2002). 
In this cluster, the incorporation of the rationales of the Industrial Revolution is evident, hence the entry point to transformation in this cluster is rather technologically driven. Nikolai Kondratieff's (1926) theory of the "Long Waves of Economic Change," or the so-called "kondratiev waves or cycles," is often cited as pioneer research work on long cycles theory. Through his studies of industrial behavior using historical facts and economic data, he argued that economic growth is not linear, but rather has a sinusoidal form. Kondratieff further argued that it was possible to forecast and foster economic growth, because cycles are found to consist of growth and decay phases, whereas market economies tend to go into the development cycle, where new technological inventions have been employed.

Further developing Kondratieff's theory and putting Kondratieff on the radar of international debate is Joseph Schumpeter's Theory of Economic Development $(1935,1954)$, which argues that changes come in the form of significant technological innovations. For example, Schumpeter refers to railway construction as the cause of another wave, because it further enhanced modern the mining industry and promoted urban development. He continues that while all economic activities are essentially repetitive and follow a familiar, routine course, changes need to take place to make the static circular flow a dynamic and discontinuous process. According to him, for this to occur, innovation is required: "spontaneous and discontinuous change in the channels of flow, disturbance of equilibrium which forever alters and displaces the equilibrium state previously existing" (Schumpeter 1934 p. 64).

Gerhard Mensch (1975) further developed Peter Schumpeter's Theory of Economic Development through his Theory of Innovation. In his 1975 publication, "Stalemate in Technology", he attributed economic stagnation to the lack of basic innovations. He identified that "basic innovations" (Basisinnovationen), as an expression of knowledge development, are the drivers of economic booms (Mensch 1971, 1972). According to him, basic innovations create new economic sectors following the introduction of new products and production processes, leading to new jobs and new sources of income. He differentiated basic innovations from "improvement-innovations" (Verbesserungsinnovation), which further develop existing sectors by reducing production costs and increasing productivity levels. Finally, the so-called "pseudo innovations" (Schein-Innovationen) are those that do not possess economic value at all. This refers to those innovations that can increase consumer wealth even though these inventions neither move demand nor supply side curves. The effects of pseudo innovations such as changing the color or original form of products to long waves or cycles are too minor, 
because they do not, for example, significantly increase final consumer satisfaction levels.

As such, the economy, which serves as a "rallying point" for technological innovations, is implied as the driving bottom line with the environment and society becoming emergent or even subservient. Several authors coming from the Great Transformation discourse tend to connect the categories, here labelled as the 'triple bottom line', in a vertical or asymmetrical manner. Some directly or indirectly claim one bottom line "dominating" or "maneuvering" the others. For example, Karl Polanyi's book "The Great Transformation" (published in 1945) (2015) pertains to the economy as a driver of the Industrial Revolution and highlights the historical evolution of the current dominance of the market economy. This book provides an important understanding of global transformation, but it only focuses on the market drivers of transformation, such as market logic, as a framing factor of the evolution. While it is difficult to imagine a society without a market-based economy, Polanyi stressed that markets are not a natural feature of human society and that there are also non-market mechanisms to distribute goods and services. The dominance of the market has emerged and cemented by certain ideologies and principles, which relate to land, labor and the market, in particular profit, and which now define the basic fibers of societies.

Others highlight one bottom line as the main driver of global transformation, while the two other bottom lines are merely responding as subordinates (or even merely as circumstances). For example, Yoshikazu Sakamoto (1994) argues in his book "Global Transformation: Challenges to the State System" that while the global economy should not be analyzed as an isolated entity, but rather in conjunction with the political society, economic drivers are both causes and effects of global and national societal conditions. In his analysis of how uneven development and democratization has led to gaps between capital internationalization and political democratization, he focuses on the importance of economic drivers to the basic framework of the modern international order. While the book provides insightful causalities between global economy and the international order, it does not provide an understanding of how uneven development affects the prospect of cooperation between actors when forging decisions. Sakamoto focuses on global transformation as driven by capital internationalization and political democratization.

Other scholars have a micro-perspective and do not clearly identify technologies as the catalyst of global transformation towards sustainability, but rather as "enablers" of transformation (see Goldemberg 1998; Bibby 2012; Guo et al. 2015). For example, Manahem Anderman (2007) identifies battery technologies for hybrid electric vehicles as an example of such "enablers" of transformation 
towards sustainability. In addition, Richard Baldwin (2016) provides an analysis of how revolutionary changes in information communication technology (ICT) has fundamentally changed globalization. Through ICT, economic, political, cultural and military power has shifted in favor of countries with emerging markets, whereas the boundaries of competitiveness between countries are increasingly controlled by firms who run international production networks. In present times, global competitiveness means countries are required to look for new impulses of economic development. Low-carbon technologies and innovations can be the new "basic innovations" that can create new industrial sectors and jobs. On the other hand, Wiebe Bijker's $(1995,2010)$ constructivist outlook on technologies claims that technologies can be "treated" or "created" differently depending on various social factors such as changing gender relationships. He calls for the establishment of a basis for science, technology, and social change that addresses the social roots of technology (Bijker 1995).

Most of the literature classified to this cluster do not clearly address social, cultural and political processes of change as being of a technological nature or determined by technology. Some authors, such as Marko Hekkert et al. (2007), are critical of the fact that while technological innovation systems are multidimensional, they do not fully address structural change and how emerging innovations struggle against existing systems (and vice-versa). They propose a method for systematically mapping processes taking place in innovation systems and resulting in technological change. In addition, Clayton Christensen et al. (2006) argue that innovations and technologies can also be disruptive. Some innovations and technologies do not bring better products to existing markets, but rather disrupt and redefine trajectories, and that increased attention needs to be given to interactions between new entrants and incumbents. As Richard Baldwin (2016) argues, an outcome of a transformation process changes the role of distance and policies. New conflict fronts are established, particularly as declining sectors and skill groups fall into disfavor, are mobilized, and struggle for their relevance. Furthermore, some challenges that currently inhibit transformation towards sustainability transcend technologies, such as changing lifestyles and preferences (see Jackson 2008; Roy et al. 2012). For example, with the ability of transportation technologies to address traffic congestion, some governments prefer "basic technologies" such as bicycles rather than expensive and less environmentally-friendly technologies. The introduction of new technologies often means the increased consumption of exhaustible natural resources, which is counterintuitive to sustainability. New voices have emerged claiming that sustainability also means less technologies or less dependence on technologies, because as new innovations are introduced, consumption increases. 


\subsection{Cluster 3: Systems Approaches (SA)- Transformation Management and Socio- Technical Discourse}

The next cluster pertains to transformation management theories (that trace their origin to the Netherlands) as well as the socio-technical transition theories. The transformation management theories highlight the goal of effectively managing transformation by taking into account complexities and the multi-tiered nature and non-concurrency of transformation processes (see Loorbach 2010; Schäpke \& Rauschmayer 2011). In the words of Rainer Grießhammer et al. (2015), this goal is motivated by the assumption that transformation processes can only unfold when the focus is not limited to technical innovations, but also includes social and institutional innovations. In addition, René Kemp et al. (1998) assert that managing transition is not only a useful option for many policy instruments, but "it may be the only feasible way to transform environmentally unsustainable regimes" (1998 p. 191).

The backdrop of this discourse is that transitions are multi-level in terms of governance. They cut across the local, national, regional and international. A significant consequence of this cross-cutting element is the emergence of several conflict cleavages, particularly when asymmetries, for example those in power, are re-aligned and relations need to be revisited. It needs to be highlighted that asymmetries are reproduced across levels. As such, the boundaries between the global, the national and the local become diffuse because of the emergence of new interdependencies. For example, the "local" assumes a "global touch" when communities, villages, towns and municipalities become recipients of technology transfer to support local sustainability projects. Best practices from these local projects will most likely be collected, inductively assessed, re-conceptualized and applied in projects in communities from other countries. An example is the use of the Talanoa Dialogue, a concept that originates from Fiji, in global negotiations pertaining to climate change (see UNFCCC 2016). In addition, the introduced technologies are expected to assume economic, social, cultural and institutional connotations (Bijker et al. 1987; Bijker 1995, 2010). New business models are sought to adequately capture the opportunities of new global-local settings. These interdependencies between levels are therefore multifaceted, non-linear and even fragmented.

The socio-technical theories emphasize the relevance and complexity of technologies and the inclusion of social relations in the analyses of technological configurations (Rip \& Kemp 1998; Geels 2005; Geels \& Schot 2007b; Geels \& Schot 2009). The inclusion of human agency as reflected by the interests, behavior, and 
preferences of humans and organizations in the analyses of technologies sets the stage for the multi-level analysis. John Grin et al. (2010) identify three initially independent action levels: megatrends, sociotechnical regimes and niche level, which allow the consideration of path dependencies along which lie processes with distinct self-contained dynamics and actors' preferences. Through these three action levels, the scope of action for change agents can be explored. Similarly, Arie Rip and René Kemp (1998) suggest three analytical levels that host non-linear processes that result from the interplay of multiple developments. The niches (1) serve as the locus for radical innovations. Sociotechnical regimes (2) pertain to the locus of established practices and associated rules that stabilize existing systems. Finally, the exogenous sociotechnical landscape (3) refers to background variables such as the material infrastructure, political culture and coalitions, social values and the natural environment.

Relevant to the linking of transition research to sustainable development is the work of John Grin et al. (2011), who argue that transformation does not only foresee new societal practices, but also changes in the structures in which these practices are embedded. They further contend that new practices need to co-evolve with earlier practices ("the regime"). Frank Geels (2011 p. 26) claims that the regime needs to be given the primary focus, because transitions are defined as shifts from one regime to another. He classifies the niche and landscape levels as "derived concepts," because "they are only defined in relation to the regime, namely as practices or technologies that deviate substantially from the existing regime" (Geels 2011 p. 26).

One major strand of socio-technical theories is the multi-level perspective (MPL), which conceptualizes overall dynamic patterns in socio-technical transitions (Geels 2011). The multi-level perspective uses a combination of evolutionary theory and the sociology of technology in explaining that transitions are shifts from one stable socio-technical regime to another. Transitions occur when regimes are destabilized through pressures (Rip \& Kemp 1998; Markard \& Truffer 2008a). Frank Geels $(2005 ; 2011)$ summarizes that MPL is an analytical framework that combines concepts from evolutionary economies (trajectories, regimes, niches, speciation, path dependence and routines), science and technology studies (sense making, social networks and innovation), structuration theory and neo-institutional theory (rules and institutions as "deep structures" from which knowledgeable actors draw their actions).

The multi-level perspective can provide relevant insights into helping developing countries, especially those countries with emerging economies such as China, India, Mexico, Brazil and Indonesia, to manage their transformation towards sustainability. By assessing the historical phases of economic, technological, 
cultural, and political changes, this multi-level perspective can help distinguish other transition patterns which destabilize the system as the transformation process unfolds. In addition, the analysis of multiple processes of "changing practices" and structural change during the course of transformation can be better aligned parallel to each other to produce non-incremental changes in practices and structures (Grin et al. 2010). Because these countries are often confronted by multiple transition processes (e.g. political, economic, post-colonial), causalities and related challenges can be better understood and resolved. For example, through this understanding, corrective measures can accompany technology transfer mechanisms to effectively target "deficient" regimes in these countries.

Through the application of the MLP, it can be inferred that sustainable, low-carbon development, as sociotechnical transition, will most likely involve alterations of various sectors such as transport, energy, and agriculture, which would entail technology policy, markets, cultural meaning and scientific knowledge. However, as Fernand Braudel (1958) argues, each of these sectors or subsystems may vary in pace and follow different historical timescales. Therefore, it is detrimental to managing transformation that the stage of transition for each sector be assessed. In addition, there are existing path dependencies that may inhibit a specific sector to support sustainable, low-carbon development. Hence, more rapid and widespread reforms are necessary to pave over path dependencies and restructure asymmetries.

New revisions of the MPL are emerging. Some of the literature is now looking at transition or transformation as a process, with various possible pathways (plurality of pathways towards one outcome) depending on different configurations and multi-level interactions (Smith 2005; Patwardhan et al. 2012). This is particularly interesting when assessing the relevance of policy models (democratic, authoritarian, hybrid) to the achievement of sustainability goals. While the MPL as an evolutionary approach on transformation entails a pre-determined "future" for a system, it also argues that changes merely reorient existing development trajectories. The regime adopts certain niche innovations into the system which leads to a gradual reconfiguration of the basic architecture including guiding principles, beliefs and practices (Smith 2005; Geels \& Schot 2007a).

Although the multi-level perspective is largely confined to emerging technologies, it can shed light on how the motivation to accept change is created. As transformation follows a specific evolutionary continuum, it is understood as an initial one-pathway, whereas challenges to the incumbent and dominant socio-technical practice (regime) will eventually emerge as the transition process unfolds. As time passes, the actors that are profiting from change will be more powerful 
than those resisting change. As more jobs are created, for example through the expansion of the renewable sector, the renewable sector will possess more resources and the confidence to pursue more effective advocacy. This is something that is being anticipated, leading to a more difficult transition process as resistance becomes a question of survival for some.

\subsection{Cluster 4: Systems Approaches (SA)—Global Shifts and Globalization Discourse}

Another cluster of how (global) transformation towards sustainability is addressed pertains to the focus on boundaries between the global and the national/local. This cluster revolves around questions about processes that support transitions and the interlocking and permeability of various domains such as state boundaries, cultures, societies, national identities and citizenship. Transformation towards sustainability is inherent to globalization, because sustainability as a concept has emerged in the context of intertwined vulnerabilities that transcend state boundaries. These intertwined vulnerabilities confront the monolithic architecture of the global system, leading to debates not only on how diplomacy can achieve solutions, but also on how the convergence of standards and identities can be facilitated to support transformation towards sustainability.

Peter Dicken (2015) points out that global shifts are mainly attributed to empirical changes in the configuration of the global economy and to changing interpretations of, and attitudes towards, 'globalization'. Barry Eichengreen (2011) attributes Great Britain's control of fully a quarter of the world's population and land mass by the end of the $19^{\text {th }}$ century to the industrial revolution, which marked a global shift. He depicts another shift in economic power from Britain to other continental countries in Europe such as Germany and France as the pretext for World War I. In the same manner, Charles Kindleberger (1973) argues that the Great Depression of the 1930s was a ramification of the global shift of power from Europe to the United States.

This shows that global shifts are to be explained in the context of power, which is manifested by how structural as well as technological changes have altered relations between countries. Barry Buzan and George Lawson (2015) highlight the impact of global transformation on international relations. They argue that the uneven distribution of economic development brought by a complex configuration of industrialization, rational state-building and ideologies of progress defines the uneven distribution of power in the international system. 
In addition, this inequity further determines the configuration of undergoing wide-ranging political, economic and cultural transformations. These global power shifts changed the basic modes of power, stimulating the emergence of global modernity.

While Joseph Nye (2010b) makes claim to the relative decline of the power of the United States, as Barry Eichengreen et al. (2008) also argue, he claims that the ongoing global shift of economic power from the United States to the East Asian region has a potentially far-reaching impact not only on markets and environmental policies, but also on reshaping relations in the current multilateral system. Several authors see a new era marked by accelerated globalization, where new decisive elements are available to maintain a leading global position (see Bardhan 2010; Kappel 2011; Shambaugh 2013; Kappel 2014). With China as the main proponent of this current global shift, the authors have pondered the emergence of new impulses for transformation towards sustainability (see Fücks 2011; Volz 2015; CCICED 2015). China's "change of tune" in climate policies is the result of the securitization of climate change (see chapter 8). This change reflects China's current, more cooperative posture in international climate policy-making as motivated by its new sociotechnical and sociolinguistic narratives.

\subsection{Cluster 5: Process Approaches (SA)-The Center- Periphery and the Global South Discourse}

Transition and transformation studies are no longer confined to European universities. Research institutions and universities in Asia and the Americas have recognized the need to establish or modify their mandates and visions and re-align their positions to be able to participate in shaping the discourse on sustainability. For example, initial contributions to leading practices in sustainability in higher education in the Asia-Pacific region have explored the trajectories of key initiatives across the region through the contextualization of sustainability innovation in higher education. Alexandra Ryan et al. (2010) attribute a wider understanding of the learning dimensions of sustainability in the region to several creative initiatives in the Asia-Pacific region that have helped harness national policy, develop further local and regional initiatives towards more profound change in curriculum development, and establish collaboration with external communities and stakeholders. As many Asian and North/South American universities and post-graduate institutes join their counterparts in Europe in establishing new, dynamic programs that integrate sustainability into 
most aspects of their curriculum including business and management, "change agents" of transformation towards sustainability are now equipped not only with concepts or ideas, but also with the technical expertise to address the emerging challenges of transformation.

The increased participation of non-European universities and research institutes in sustainability discourse will most likely lead to challenges to existing well-established Euro- or West-centric assumptions about sustainability. Old evidence paired with old approaches will most likely be revisited and new ways of linking will emerge, particularly because of the inter- and trans-disciplinarity of sustainability studies. For example, trajectories of sustainable development tend to "favor" democratic or deliberative (consensus-building) policy models (see Baber \& Bartlett 2005; Arias-Maldonado 2007; Purdy 2010). Nevertheless, selected case studies in the book, particularly the case studies on Mexico, China and the Philippines offer new ways of re-linking 'modern' policy models with sustainability.

Some questions arise as to whether alternative perspectives such as the 'Indigenous' Modernity (see Pratt 2002; Ravindran 2015), the 'Asian Way' (Dupont 1996; see Chesterman \& Mahbubani 2010) and Bienestar (see Collier \& Collier 1991; Feinberg et al. 2006; Etcheverry 2011) could be equally useful for studies of transformation towards sustainability. For example, Simon Chesterman and Kishore Mahbubani (2010) argue that while there is no coherent or systematic Asian approach to meeting global challenges, Asian policy-making tends to respond pragmatically to challenges and is less ideology-driven. This includes how Asian countries such as Japan, with its "reluctant realism" towards China (Green \& Self 1996), address changes in the region.

Another strand of this cluster refers to linking the study sustainability transformation to the development of the welfare state, which has been made prominent in Latin American literature through the concept, "estado del bienestar" (state-of-well-being) (see André 2008; Seligman 2014). This strand is a proponent of the ideas of Abraham Maslow (1943), who suggested the pyramid of basic needs. In addition, this strand calls for political actors to pursue the enhancement of four areas of health: physical, mental, emotional and social (see Smith et al. 2012; Abers \& Tatagiba 2014). The "wellness" concept may open more channels for discourse on transformation towards sustainability, because most societies, particularly in developing countries, have had a long-standing debate on welfare policies such as Zakat (charity) in Islamic Law and Dharma (path) in India that could be used to further promote sustainability policies (see Shadi 2003; Crone 2005). 
As the understanding of transformation or transition towards sustainability is widely contextualized, it has become apparent that differences in approaches and Weltbilder (world views) exist that require the re-visitation of existing concepts. As some developing countries that demonstrate advancement in their transformation towards sustainability deviate from the ideal type of democratic policy models as the "formula" for successful transformation (see Baber \& Bartlett 2005; Arias-Maldonado 2007), there is a need to revisit, among others, the 'purposive rationality' (Zweckrationalität) of sustainability. As proposed by Max Weber (2005), expectations are developed as a means for a particular actor to attain rationally-pursued and calculated ends. In this sense, while transformation is driven by "social actions" serving a particular end, preferences around policy models can be diverse. Following the 'value-free' argument of global transformation in their book "Global Transformation and the Third World," Robert Slater, et al. (1993) suggest that while the major element of global transformation pertains to democratization (the wave of political liberalization), the 'Third World' perspective may highlight military rule as the major alternative to democracy in most 'Third World' countries where military regimes can be, equally, both 'credible' as well as effective and efficient administrators. Therefore, when reflecting on sustainable, low-carbon transformation, a 'value-free' perspective on assessing sustainability pathways seems to be viable. This suggests that processes that are not built on consensus-building can also be practically used to achieve sustainability priorities.

\subsection{Cluster 6: Process Approach-The Climate Negotiations Discourse}

Another cluster can be identified, one that evolves around the discourse framed by or for climate negotiations, where major conflict cleavages, as reflected by the numerous bilateral and multilateral climate negotiations, are related to the perceived economic burdens of climate mitigation and adaptation as major pillars of addressing climate change (see Cullet 1998; Heyward 2007; Penetrante 2010). The demand from developing countries for exemptions or delays in their mitigation commitments due to their right to develop (see Ott et al. 2004; Kanitkar et al. 2010; Najam 2010; Penetrante 2010) collides with the demands of developed countries that developing countries make comparable commitments to mitigation (see Winkler et al. 2009a; Penetrante 2010, 2013). As such, the academic debate has focused its attention on the nexus economy and the environment as well as on 
the nexus society and the environment when addressing climate mitigation and adaptation.

Some authors have observed that the global transformation towards sustainability is currently framed by global negotiations, particularly the climate change negotiations (see Sjöstedt 1993; Sjöstedt \& Penetrante 2013) and the multilateral process towards sustainable development (see Kalhauge et al. 2005). As climate negotiations proceed, problems come to light, agendas are defined and procedures of generating solutions emerge as outcomes of these negotiations. The tendency within debate has now moved forward towards the 'decoupling' of the three bottom lines (see Steinberger \& Roberts 2010), as doing so is perceived to create the political will to commit to climate protection. In this regard, a number of studies now support the notion that a climate-compatible global economy is technologically possible (see McKinsey 2009; GEA 2012). For example, the International Energy Agency (IEA) (2016b) reported that global $\mathrm{CO}_{2}$ emissions from energy-related activities have not risen since 2013 in spite of global economic growth, suggesting that the decoupling of emissions and economic activity is possible. The stabilization of emissions was attributed to the registered 1.5 percent decline in emissions in the United States and China.

A major obstacle to climate protection, and therefore also for low-carbon development, is primarily the 'undoing' of narratives and the perception of additional constraints, for example to food security and living space, particularly for countries already struggling to meet their needs. Because the discourse on climate mitigation in most countries is dominated by narratives of climate protection, for example exacerbating food insecurity, policy-makers focus on trade-offs rather than co-benefits. Some scholars question these narratives and argue that, with efficient structural changes including the promotion of inclusive participation (see Winslow 2005), food insecurity does not need to be an issue. For example, Julia Steinberger and J. Timmons Roberts (2010) highlight the possibility of decoupling of energy and carbon from human needs such as food and shelter. If the academic discourse on the decoupling of the three bottom lines is able to find a consensus that there are co-benefits to pursuing climate protection policy goals for the two other bottom lines (economy and society), negative externalities can be reduced or even prevented. Nevertheless, decoupling requires a more integrated understanding of causalities and process-tracing. For this, new methods of assessment and verification are needed to be developed and to mature, which requires more time and testing.

For scholars working on path dependencies, decoupling means identifying carbon lock-ins, particularly in the economy, which hinder the sets of viable solutions 
that support sustainability, including climate protection. New approaches are needed to recalculate economies of scale, revisit coordination and collaboration problems and redefine the impacts of policies (or the lack of them). As Claus Leggewie and Dirk Messner (2012 p. 10) maintain, the successful implementation of transitions towards sustainability will be highly dependent on cognitive models, concepts and narratives that foresee how "change agents" acquire power to realign the economy and society. There is still, however, the need to move one step 'sideways' and link this newly acquired power with a debate about justice and fairness. Existing formal and informal rules as well as norms will need to be improved to adequately address this newly acquired power. Transformation needs to be legitimized by the society, but this legitimization needs to be preceded by a "tolerable window" (see Bruckner et al. 1998; Bruckner et al. 1998; Petschel-Held et al. 1999). In addition, the temporal dimension of decoupling, for example, climate protection from the economic burdens of mitigation, necessitates the careful planning of stages and complementary mechanisms to absorb and make sense of the incremental learning process.

\subsection{Interim Conclusion}

This chapter contributes to this book's theoretical framework by identifying parameters for the knowledge tools (ideal types and case studies/simulation). The rationale behind the introduction of the six different clusters is to rethink boundaries, even between relevant debates surrounding transformation towards sustainability, in order to effectively establish frameworks. The six different clusters allow a clear comparison in terms of context (a systems perspective, by focusing on entry points and drivers), agency (the power and purpose, by highlighting anchors for the deliberation process) and audience (in reference to legitimacy and the social contract vis-à-vis the transformation process).

Interestingly, the differences between these clusters of debates are themselves results of the contextuality of the process of academic debate. While looking at these differences, it can be argued that some difficulties in designing and implementing sustainability policies can be attributed to the continuous development of a specific debate. For example, while the debate surrounding climate change negotiations problematizes the coupling of climate protection goals with developmental goals (emission reduction can be achieved with increased economic development), the debate surrounding sustainable development calls for a much closer coupling of climate protection and developmental policies. For many developed countries, climate mitigation assistance to developing countries should 
be counted as official development assistance. For most developing countries, climate mitigation assistance from developed countries should be counted in addition' to official development assistance. Furthermore, because the audience of climate protection policies does not always correspond to the audience of sustainable development policies, some gaps between policy outcomes arise. There are different types of resistance within a specific debate that might later limit the usefulness of concepts to policy-making. This 'anti-climax' following intense debate can lead to frustration and resignation.

Open Access This chapter is licensed under the terms of the Creative Commons Attribution 4.0 International License (http://creativecommons.org/licenses/by/4.0/), which permits use, sharing, adaptation, distribution and reproduction in any medium or format, as long as you give appropriate credit to the original author(s) and the source, provide a link to the Creative Commons license and indicate if changes were made.

The images or other third party material in this chapter are included in the chapter's Creative Commons license, unless indicated otherwise in a credit line to the material. If material is not included in the chapter's Creative Commons license and your intended use is not permitted by statutory regulation or exceeds the permitted use, you will need to obtain permission directly from the copyright holder.

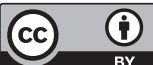

